\title{
Eddy-covariance flux errors due to biases in gas concentration measurements: origins, quantification and correction
}

\author{
G. Fratini ${ }^{1}$, D. K. McDermitt ${ }^{1}$, and D. Papale ${ }^{2,3}$ \\ ${ }^{1}$ LI-COR Biosciences Inc., Lincoln, Nebraska, USA \\ ${ }^{2}$ Department for Innovation in Biological, Agro-food and Forest systems (DIBAF), University of Tuscia, Viterbo, Italy \\ ${ }^{3}$ Euro-Mediterranean Center on Climate Change (CMCC), Via Augusto Imperatore 16, 73100 Lecce, Italy
}

Correspondence to: G. Fratini (gerardo.fratini@licor.com)

Received: 13 June 2013 - Published in Biogeosciences Discuss.: 19 August 2013

Revised: 9 December 2013 - Accepted: 20 December 2013 - Published: 21 February 2014

\begin{abstract}
Errors in gas concentration measurements by infrared gas analysers can occur during eddy-covariance campaigns, associated with actual or apparent instrumental drifts or biases due to thermal expansion, dirt contamination, aging of components or errors in field operations. If occurring on long timescales (hours to days), these errors are normally ignored during flux computation, under the assumption that errors in mean gas concentrations do not affect the estimation of turbulent fluctuations and, hence, of covariances. By analysing instrument theory of operation, and using numerical simulations and field data, we show that this is not the case for instruments with curvilinear calibrations; we further show that if not appropriately accounted for, concentration biases can lead to roughly proportional systematic flux errors, where the fractional errors in fluxes are about $30-40 \%$ the fractional errors in concentrations. We quantify these errors and characterize their dependency on main determinants. We then propose a correction procedure that largely - potentially completely - eliminates these errors. The correction, to be applied during flux computation, is based on knowledge of instrument calibration curves and on field or laboratory calibration data. Finally, we demonstrate the occurrence of such errors and validate the correction procedure by means of a field experiment, and accordingly provide recommendations for in situ operations.
\end{abstract}

\section{Introduction}

For the past $20 \mathrm{yr}$, the eddy-covariance technique has been widely used to measure exchange fluxes of mass and en- ergy between ecosystems and the atmosphere (Aubinet et al., 2012). Nowadays there are about 500 operational eddycovariance stations worldwide, organized in continental networks and contributing to the global FLUXNET network (http://fluxnet.org/). These stations - mainly concentrated in Europe and US, where sites with the longest time series are located - have provided unique data about carbon, water and energy exchanges at spatial scales of tens to hundreds of metres around the measurement point, with a typical time resolution of 30 to $60 \mathrm{~min}$. These data have been extensively used by the scientific community for ecological studies (see, e.g. Baldocchi, 2008; Mahecha et al., 2010; Reichstein et al., 2007) and modelling purposes (see Beer et al., 2010; Jung et al., 2010; Bonan et al., 2011). In recent years, development of new instrumentations opened the applicability of eddy covariance also to other greenhouse gases (McDermitt et al., 2011; Baldocchi et al., 2012; Detto et al., 2011), contributing to the development of long-term monitoring networks such as NEON (www. neoninc.org), ICOS (www.icos-infrastructure.eu) and AmeriFlux (http://ameriflux.lbl.gov).

Estimation of gas fluxes with the eddy-covariance technique requires the use of fast, precise gas analysers. Precision here means that the instrument is able to discriminate small variations of gas concentration. This metrological quality is crucial for the measurement of ambient fluctuations, necessary to calculate turbulent vertical fluxes $\left(F_{x}, \mathrm{~mol} \mathrm{~m}^{2} \mathrm{~s}^{-1}\right)$ according to the eddy-covariance equation which, in the ideal case, takes the following form (Baldocchi, 2003):

$F_{x}=\rho_{\mathrm{d}} \overline{w^{\prime} x^{\prime}}$ 
where $\rho_{\mathrm{d}}\left(\mathrm{kg} \mathrm{m}^{-3}\right)$ is density of dry air, $w\left(\mathrm{~m} \mathrm{~s}^{-1}\right)$ vertical wind speed, and $x\left(\mathrm{~mol} \mathrm{~mol}^{-1}\right)$ gas mixing ratio (i.e. gas concentration expressed as the ratio of the moles of gas to the moles of dry air). In Eq. (1) primes denote turbulent fluctuations, evaluated around an appropriate average (Rannik and Vesala, 1999), and the overbar denotes the averaging operator. Wind speed and concentration fluctuations must be measured precisely, and fast enough to sample all relevant turbulent motions exhaustively, typically at 10 to $20 \mathrm{~Hz}$.

In contrast to precision, accuracy - the metrological quality of nearing the true value of a quantity - is generally regarded as less critical by eddy-covariance investigators, under the assumption that constant or slowly changing biases in gas concentration measurements do not affect the estimation of turbulent fluctuations and thus do not affect resulting fluxes. For the same reason, to the knowledge of the authors, attempts to quantify potential errors due to these biases have not been undertaken. We will show that because instrument calibration functions are curvilinear, even a constant bias in the measurement of absorptance implies not only a bias in the estimation of mean gas concentrations, but also a bias in the estimation of turbulent fluctuations, thereby affecting fluxes calculated according to Eq. (1). To understand the reason, it is necessary to consider some elements of the theory and calibration of non-dispersive infrared gas analysers (IRGAs).

Non-dispersive infrared (NDIR) gas analysers long have been used for ecosystem flux measurements, and today virtually all eddy-covariance towers worldwide deploy such instruments for measuring fluxes of $\mathrm{CO}_{2}$ and latent energy $(L E)$. Examples of such analysers are the LI-7000, LI-7500, LI-7200 (LI-COR Biosciences Inc., Lincoln, NE, USA) and the EC150 (Campbell Scientific Inc., Logan, UT, USA). IRGAs estimate the concentration of a given gas by measuring absorptance, which is the fraction of radiation the gas absorbs in a specified spectral range, over a known path length in a specified volume of air. Absorptance is then converted into an estimate of gas number density or mole fraction by means of a calibration curve, which can be expressed in either quantity. Typically, number density is used for open-path instruments and mole fraction for closed-path instruments.

The relationship between absorptance and concentration is a spectroscopic property of the absorbing gas under the conditions of measurement. Broadband absorption is the result of contributions from a large number of individual spectral lines, which have varying degrees of saturation and overlap. The relationship is nonlinear and cannot be predicted theoretically by any single analytical function. Absorption by an individual spectral line follows Beer's law, but broadband absorption does not over typical measurement ranges. Therefore, this nonlinear relationship is described with an empirical function, typically a polynomial, although other forms can also be used. The calibration function is constructed by fitting the function to a series of number densities, each divided by pressure $\left(\rho / P, \mathrm{~mol} \mathrm{~m}^{-3} \mathrm{kPa}^{-1}\right)$, and corresponding measured absorptances, each divided by $P\left(a / P, \mathrm{kPa}^{-1}\right)$.
The calibration function $F$ can be expressed in terms of number density or mole fraction (for closed-path analysers). For open-path analysers and the LI-7200,

$\rho=P F\left(\frac{a}{P}\right)$.

Or, for closed-path analysers such as the LI-7000, after substituting $\rho=\chi P /(R T)$,

$\chi=T G\left(\frac{a}{P}\right)$,

where $\chi$ is mole fraction of absorbing gas ( $\mathrm{mol}(\mathrm{mol} \text { air })^{-1}$ ), $T$ absolute temperature (K), and the gas constant $R$ is subsumed into the function $G$. Equations (2) and (3) present number density or mole fraction as single-valued functions of absorptance over a wide range of gas concentrations, temperatures and pressures. They can be derived empirically (McDermitt et al., 1993), but they can also be confirmed with calculations using detailed spectroscopic models, such as HITRAN (Rothman et al., 2009). Calibration in mole fraction requires temperature of the gas to be known, which it usually is for closed-path instruments, and it has strong pressure dependence. Calibration in number density does not require gas temperature to be known, and the pressure dependence is much weaker.

While the spectroscopic relationship between $\rho / P$ and $a / P$ is the main determinant of the shapes of calibration curves, these curves can also vary between individual instruments. This arises because of small spectral variations in sources, lens chromatic aberrations, variations in optical filters, detector heterogeneities, and other things. Thus each instrument will have its own calibration function, and these curves will vary somewhat from instrument to instrument. Fitting parameters are established for each production unit (i.e. each serial number) by means of a factory calibration procedure.

Finally, number densities and mole fractions can be converted into dry mole fractions (or mixing ratios, see Appendix A) if temperature, pressure, and water vapour mole fraction in the measuring volume are measured at the same frequency as the gas measurement. This is the case, for example, with the LI-7200 (Burba et al., 2012). Otherwise, effects of changing air densities must be accounted for following, for example, the approach of Webb et al. (1980). In the following we will refer to either mole fraction or number density, with the understanding that air density fluctuations are duly taken into account when changing between the two.

\section{Materials and methods}

Eddy-covariance measurements require that gas analysers be deployed either on towers exposed to ambient air, or else have ambient air drawn through them at a high rate. Both of these configurations are subject to contamination from particulate matter and aerosols in the ambient air. 
Source

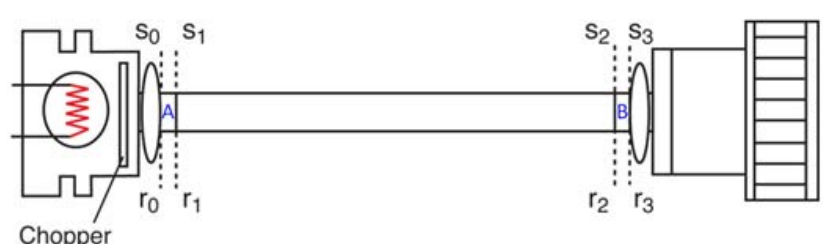

Fig. 1. General layout of an infrared gas analyser optical path. Symbols $s_{i}$ and $r_{i}$ represent optical power in the sample and reference paths, respectively, at position $i$ in the path. The sample and reference paths can be in the same physical space but with different wavebands, as in a dual-wavelength, single-path instrument (e.g. LI7500); or in the same waveband but in different physical paths, as in a dual-path, single-wavelength instrument (e.g. LI-7000). The paths between $S_{0}$ and $S_{1}$ (window $A$ ) and between $S_{2}$ and $S_{3}$ (window B) represent windows, while the path between $S_{1}$ and $S_{2}$ represents the gas flow path.

Wells and McDermitt (2005) describe two IRGA designs: "dual-path, single-wavelength" instruments (e.g. LI7000) and "dual-wavelength, single-path" instruments (e.g. LI-7500, LI-7200). Contamination affects the two designs somewhat differently. In the first case, any contamination has a first-order impact on reducing transmittance because it only affects the sample cell. Thus, these types of instruments are very sensitive to contamination, and biases are only positive. Such instruments must always be operated with filters in place. By contrast, for dual-wavelength, single-path instruments like the LI-7500 and the LI-7200, contamination attenuates both the sample and reference wavelengths, and to first order this attenuation divides to unity when the ratio is constructed. Thus, instruments with the latter design can often operate in dirty environments without the use of air filters; however, a problem can arise if second-order effects cause the normalization to be imperfect. For example, depending upon particle size, shape, and refractive index, different types of contamination can cause greater or lesser scattering at either the sample or reference wavelengths causing the ratio to be either greater or less than unity and resulting offsets to be either positive or negative (Serrano-Ortiz et al., 2008). Also, offsets in the $\mathrm{CO}_{2}$ and $\mathrm{H}_{2} \mathrm{O}$ channels can vary independently and even with opposite signs.

But in all cases, the result of any offsets is to cause a shift on the absorptance axis, and because the relationship between gas concentration and absorptance is nonlinear, a change in slope, which defines sensitivity to small fluctuations in gas concentration. This change in sensitivity has two consequences. First, because the slope of the calibration curve increases with $\mathrm{CO}_{2} / \mathrm{H}_{2} \mathrm{O}$ concentration, any zero offset will have a larger effect at ambient concentrations (Fig. 2), and adjusting zero will remove most or all of apparent drifts. Second, since offsets affect sensitivity to small $\delta x$, they will propagate into $x^{\prime}$ in Eq. (1), and therefore into flux estimates.
Biases in absorptance also can arise from causes other than contamination, including the following: (1) actual instrumental errors due, for example, to temperature sensitivity, errors in pressure correction, aging of electronic and mechanical components; (2) apparent instrumental errors due to aging of disposable chemical scrubbers; or (3) inaccuracies in calibration procedures. Different causes can lead to biases characterized by different patterns. For example, temperature sensitivity creates biases characterized by a pronounced correlation to environmental patterns (e.g. diurnal temperature cycles), but typically bounded to limited concentration oscillations (see also Sect. 3.3.1). By contrast, contaminant deposition on the optical path can lead to large biases, which are however normally not correlated to environmental drivers of interest. During field calibration, two parameters are adjusted to mathematically offset (the "zero" parameter) or amplify (the "span") the native instrumental absorptance reading, so as to match the known reference on the calibration curve. Although maximum effort is often made to keep the analysers clean and calibrated, inaccuracies in the field calibration procedures can be a source of both zero and span uncertainties. In addition, for stations located in remote areas that are difficult to reach and in challenging environments, calibration and maintenance often cannot be performed with due regularity.

In this work we investigate absorptance biases originating from any of these sources, and their effects on fluxes. By means of numerical simulations, we quantify errors in flux estimations induced by biases in measured gas absorptances and characterize flux error dependency on baseline (actual) gas concentration, magnitude of absorptance bias, and shape of the calibration curve with the aim to (1) test our theory using field measurements, (2) propose and validate a correction methodology to be used during post-field raw data processing that avoids or minimizes flux errors, and (3) provide recommendations to minimize errors during data collection.

As we will see, the proposed correction procedure is, in essence, the inverse of the error simulation, and was developed after the results of the numeric exercise were analysed and understood. Here we present our work with the same logic: in the present section we describe the error simulation, discuss its results and derive the correction procedure as a consequence. In the results section, instead, we focus the discussion on the improvements obtained by applying the correction to a test case.

\subsection{Numerical analysis of concentration and flux errors}

\subsubsection{Errors in gas concentration fluctuations}

With reference to Fig. 1, the optical power entering the optical path of an IRGA in the sample channel is $s_{0}$, and optical power in the reference channel is $r_{0}$. Optical power reaching the detector in the sample or reference channels is $s_{3}$ or $r_{3}$, respectively. The instrument measures transmittance $\left(\tau_{\mathrm{m}}\right)$ 


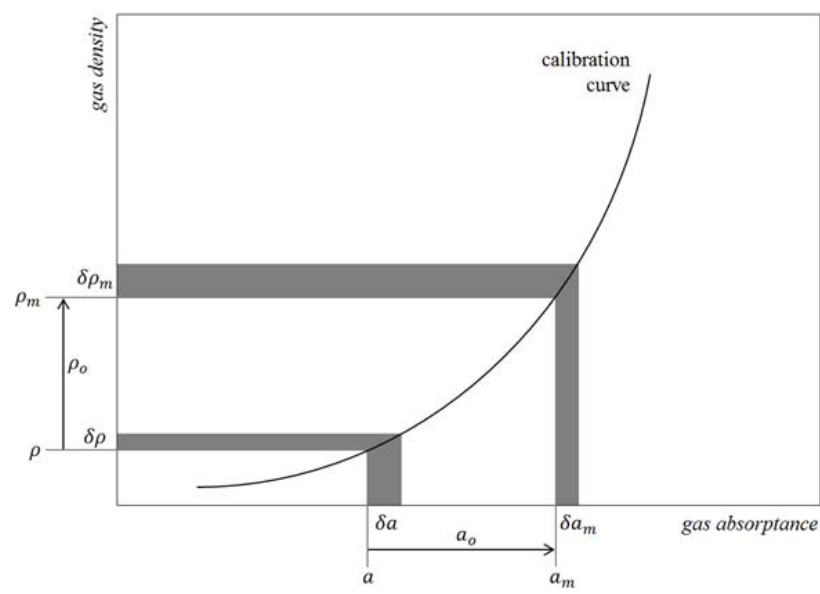

Fig. 2. Conceptual visualization of how a zero bias in gas absorptance $\left(a_{0}\right)$ yields an accuracy bias in gas density $\left(\rho_{0}\right)$ as well as a precision bias in the evaluation of density fluctuations $\left(\delta \rho_{\mathrm{m}} \neq \delta \rho\right)$. Note that $\delta a_{\mathrm{m}}<\delta a$ in Eq. (11). The curvature of the calibration curve, the magnitude of absorptance bias, and the attenuation of $\delta a_{\mathrm{m}}$ relative to $\delta a$ are all exaggerated for the purpose of illustration.

through the system as

$\tau_{\mathrm{m}}=\frac{s_{3}}{r_{3}}$.

The air sample is contained in the volume between the two windows $\mathrm{A}$ and $\mathrm{B}$, while all other volumes are kept free of $\mathrm{CO}_{2}$ and $\mathrm{H}_{2} \mathrm{O}$. Transmittance through any compartment of the sample optical path (from position $i-1$ to position $i$ ) is given by $s_{i} / s_{i-1}=\tau_{\mathrm{si}}$, and for the reference path by $r_{i} / r_{i-1}=$ $\tau_{\text {ri }}$, so for the catena shown in Fig. 1,

$\frac{s_{3}}{r_{3}}=\frac{s_{0}}{r_{0}} \frac{\frac{s_{1}}{s_{0}}}{\frac{s_{1}}{r_{0}}} \frac{\frac{s_{2}}{s_{1}}}{\frac{r_{2}}{r_{1}}} \frac{\frac{s_{3}}{s_{2}}}{\frac{r_{3}}{r_{2}}}=\frac{s_{0}}{r_{0}} \frac{\tau_{s 1}}{\tau_{r 1}} \frac{\tau_{s 2}}{\tau_{r 2}} \frac{\tau_{s 3}}{\tau_{r 3}}$

Absorptance ( $a$ ) by the gas of interest in the reference path is zero, and since by definition $a+\tau=1$, it follows that $\tau_{r 2}=1$. Thus,

$\tau_{\mathrm{m}}=\frac{s_{0}}{r_{0}} \frac{\tau_{s 1}}{\tau_{r 1}} \frac{\tau_{s 3}}{\tau_{r 3}} \tau_{s 2} \equiv \frac{1}{z_{0}} \tau$,

where $\tau_{s 2}(=\tau)$ is transmittance through the sample gas, and $\tau_{\mathrm{si}}$ and $\tau_{\mathrm{ri}}$ are transmittances through the two windows $\mathrm{A}$ and $\mathrm{B}$ in the sample and reference paths, respectively. The coefficient $z_{0}$ reflects the initial spectrum and optical power entering the system, as well as transmittances through the windows of the sample and reference paths. Equation (6) shows that transmittance measured as $s_{3} / r_{3}$ is proportional to the transmittance of the absorber gas in the optical cell of the analyser, as long as the source ratio $\left(s_{0} / r_{0}\right)$ is stable and the ratios of sample and reference transmittances through the windows $\left(\tau_{s 1} / \tau_{r 1}\right.$ and $\left.\tau_{s 3} / \tau_{r 3}\right)$ remain constant.
In operation, gas analysers measure absorptance as $a_{\mathrm{m}}=$ $1-z \tau_{\mathrm{m}}$, where $z$ is an adjustable parameter that enables a zero adjustment. Substituting Eq. (6) in this expression,

$a_{\mathrm{m}}=1-\frac{z}{z_{0}} \tau$.

When absorber concentration is zero, transmittance is unity, and

$a_{0}=1-\frac{z}{z_{0}}$

For a clean instrument, setting the zero during calibration consists of flowing a zero gas through the instrument and adjusting the coefficient $z$ so that $a_{0}=0$, which sets $z=z_{0}$; however, if an instrument becomes contaminated such that $z \neq z_{0}$, then a positive or negative offset $a_{0}$ will develop.

Equation (7) can also be written in terms of absorptance because $a+\tau=1$. Thus, $a_{\mathrm{m}}=1-\frac{z}{z_{0}}(1-a)$, or

$a_{\mathrm{m}}=a_{0}+\frac{z}{z_{0}} a$

As long as the source remains stable and the ratios of sample and reference transmittances through the windows do not change, $z=z_{0}$, and Eq. (9) can be seen to reduce to Eq. (7).

Combining Eqs. (8) and (9) gives

$a=\frac{a_{\mathrm{m}}-a_{0}}{1-a_{0}}$.

Equation (10) provides a convenient way to compute true absorptance from measured absorptance $\left(a_{\mathrm{m}}\right)$ and any absorptance offset, $a_{0}$.

Typically, the source output remains quite stable over time, but windows can become contaminated. If the contamination is such that the ratios $\tau_{\mathrm{si}} / \tau_{\text {ri }}$ change, then $z_{0}$ will shift and $z$ will no longer equal $z_{0}$, with two effects: an offset $a_{0}$ will develop, and absorptance $a$ will be multiplied by $z / z_{0}$. In practice, the offset $a_{0}$ has a larger effect on the measurement because in that case, $z / z_{0}$ operates on unity (Eq. 8) and adds to absorptance (Eq. 9), whereas as a scalar, $z / z_{0}$ multiplies absorptance, which is typically an order of magnitude smaller. For example, a shift in $z / z_{0}$ from unity to 0.999 will create an offset of 0.001 , which will add to an absorptance of about 0.0875 at $400 \mu \mathrm{mol} \mathrm{mol}^{-1}$, using a typical calibration function. This along with multiplying absorptance by 0.999 will cause about a $5 \mu \mathrm{mol} \mathrm{mol}^{-1}$ shift from 400 to $405 \mu \mathrm{mol} \mathrm{mol}^{-1}$. By contrast, simply multiplying absorptance by 0.999 only causes a $0.5 \mu \mathrm{mol} \mathrm{mol}^{-1}$ shift to $399.5 \mathrm{ppm}$.

Finally, the impact of a shift in zero offset on measured absorptance fluctuations can be found by differentiating Eq. (9). Taking $z_{0}$ as constant on the timescale of fluctuations, we can write

$\delta a_{\mathrm{m}}=\frac{z}{z_{0}} \delta a=\left(1-a_{0}\right) \delta a$. 
We now consider how the bias $a_{0}$ affects the computation of number density on the calibration curve. Equation (2) can be rewritten more rigorously as

$$
\frac{\rho}{P_{\mathrm{e}}}=F\left(\frac{a}{P_{\mathrm{e}}} \mid c_{0} \ldots, c_{n},\right)
$$

where $P_{\mathrm{e}}(\mathrm{Pa})$ is the equivalent pressure (Jamieson et al., 1963). For a given analyser model and a given gas, the order $n$ of the calibration polynomial $F$ is normally fixed, while fitting coefficients $c_{0} \ldots \mathrm{c}_{n}$ are optimized for each individual unit during factory calibration. Increases in pressure cause increased line broadening and line overlap, which increases broadband light absorption. Different gas species affect line broadening differently, but the composition of the atmosphere is nearly constant, except for $\mathrm{CO}_{2}$ and water vapour. Variations in $\mathrm{CO}_{2}$ partial pressure are small so their effects on pressure broadening can be neglected, but variations in water vapour can be several per cent and must be considered. Equivalent pressure compensates for such variations (Welles and McDermitt, 2005). For reference, $P_{\mathrm{e}}=$ $P\left(1+\left(\alpha_{\mathrm{w}}\right) \chi_{\mathrm{w}}\right)$, where $\alpha_{\mathrm{w}}$ is a foreign gas broadening coefficient for water vapour, which varies for different instrument models $\left(1.1<\alpha_{\mathrm{w}}<1.6\right)$, and $\chi_{\mathrm{w}}$ is the mole fraction of water vapour in moist air.

For the sake of readability, in the following we assume that parameters $c_{0} \ldots c_{n}$ are fixed in time, and we consider $\rho$ and $a$ already normalized by the equivalent pressure $P_{\mathrm{e}}$, so we can write

$\rho=F(a)$.

Assuming constant temperature and pressure in the optical path of a clean and calibrated instrument $\left(z / z_{0}=1, a_{0}=0\right)$, we now imagine that the number of moles of the gas in the optical path increases (or decreases) to determine a variation of absorptance $\delta a$ around $a$. From Eq. (13) we can determine how number density is affected as a result:

$\rho+\delta \rho=F(a+\delta a)$,

with the density variation being given by

$\delta \rho=F(a+\delta a)-F(a)$.

Let us now assume, instead, that the same happens in an uncalibrated or dirty instrument (i.e. in an instrument affected by an absorptance bias $a_{0} \neq 0$ ). Then, Eq. (15) becomes

$\delta \rho_{\mathrm{m}}=F\left(a_{\mathrm{m}}+\delta a_{\mathrm{m}}\right)-F\left(a_{\mathrm{m}}\right)$

where $a_{\mathrm{m}}$ and $\delta a_{\mathrm{m}}$ are given by Eqs. (9) and (11) respectively, with $z / z_{0} \neq 1$.

Note that variation $\delta \rho_{\mathrm{m}}$ is different from $\delta \rho$ for at least two reasons, and possibly three. First, as long as the polynomial $F$ is of an order different from 1 (i.e. it is not linear), the sensitivity $\delta \rho / \delta a$ increases with increasing $a$, as shown in
Fig. 2. Thus, in the presence of a positive offset $a_{0}$, equivalent fluctuations in $a$ cause larger fluctuations in $\rho$ because sensitivity is greater at $a+a_{0}$ than it is at $a$. The error of too large fluctuation estimates in $\rho$ would propagate into flux calculations. Second, as already mentioned, $z / z_{0}$ scales $a$. This is a smaller effect and goes in the opposite direction from the first. Third, a change in $z_{0}$ implies a different effect of contamination on the sample and reference transmittances, which further implies at least the possibility of a change in the light spectrum entering in the sample path. If the spectral content of light in the sample path changes, then integrated spectral absorption by the gas of interest could be altered, possibly changing the shape of the calibration curve. This is difficult to assess inasmuch as its effects would combine with those just mentioned and would likely vary with the nature and amount of contaminants. The latter effect will be ignored in this paper.

The difference between $\delta \rho_{\mathrm{m}}$ and $\delta \rho$ is the error in the estimation of gas density fluctuations, denoted as $\epsilon_{f}$ in the following. If not corrected, this error propagates through the data processing to contaminate fluxes. Expressed in relative terms, the error is

$$
\begin{aligned}
\epsilon_{f} & =\frac{\delta \rho_{\mathrm{m}}-\delta \rho}{\delta \rho} \cdot 100 \\
& =\frac{F\left(a_{\mathrm{m}}+\delta a_{\mathrm{m}}\right)-F\left(a_{\mathrm{m}}\right)-[F(a+\delta a)-F(a)]}{F(a+\delta a)-F(a)} \cdot 100 \\
& =\frac{F\left(a_{0}+\frac{z}{z_{0}} a+\frac{z}{z_{0}} \delta a\right)-F\left(a_{0}+\frac{z}{z_{0}} a\right)-[F(a+\delta a)-F(a)]}{F(a+\delta a)-F(a)} \cdot 100 .
\end{aligned}
$$

Equation (17) highlights that $\epsilon_{f}$ depends on (1) the shape of the curve $F$, in particular on its degree of curvature; (2) the starting ("baseline") absorption $a$, i.e. the point on the curve $F$ where the variation is evaluated; (3) the amount of offset in $z$ and $a_{0}$; and (4) the intensity of the absorptance fluctuation $\delta a$. Figure 3 shows the evolution of $\epsilon_{f}$ according to Eq. (17) for positive biases. The calibration curves chosen for these plots are those with median curvature among the population of calibration curves for $\mathrm{CO}_{2}$ and $\mathrm{H}_{2} \mathrm{O}$ of all LI-7200 units produced between 2010 and 2012. Curvature was estimated in the concentration ranges of typical environmental interest (200 to $1000 \mu \mathrm{mol} \mathrm{mol}^{-1}$ for $\mathrm{CO}_{2}$ and 0 to $30 \mathrm{mmol} \mathrm{mol}^{-1}$ for $\mathrm{H}_{2} \mathrm{O}$ ) by means of the departure from linearity as measured by the Pearson coefficient. For readability, the error is presented here as a function of concentrations (baseline and bias) rather than absorptances. Note that for $\mathrm{CO}_{2}$ we use mean mole fraction relative to dry air, which is equivalent to mixing ratio, while for water vapour we use mean mole fraction relative to moist air. These units are chosen because they best represent the physical processes driving instrument response. Furthermore, they are either the native units used to calibrate the instruments or are proportional to them by use of the ideal gas law, without further manipulation.

It can be recognized that the error changes with the baseline concentration much more dramatically for $\mathrm{H}_{2} \mathrm{O}$ than for $\mathrm{CO}_{2}$, on account of the stronger curvature of the 

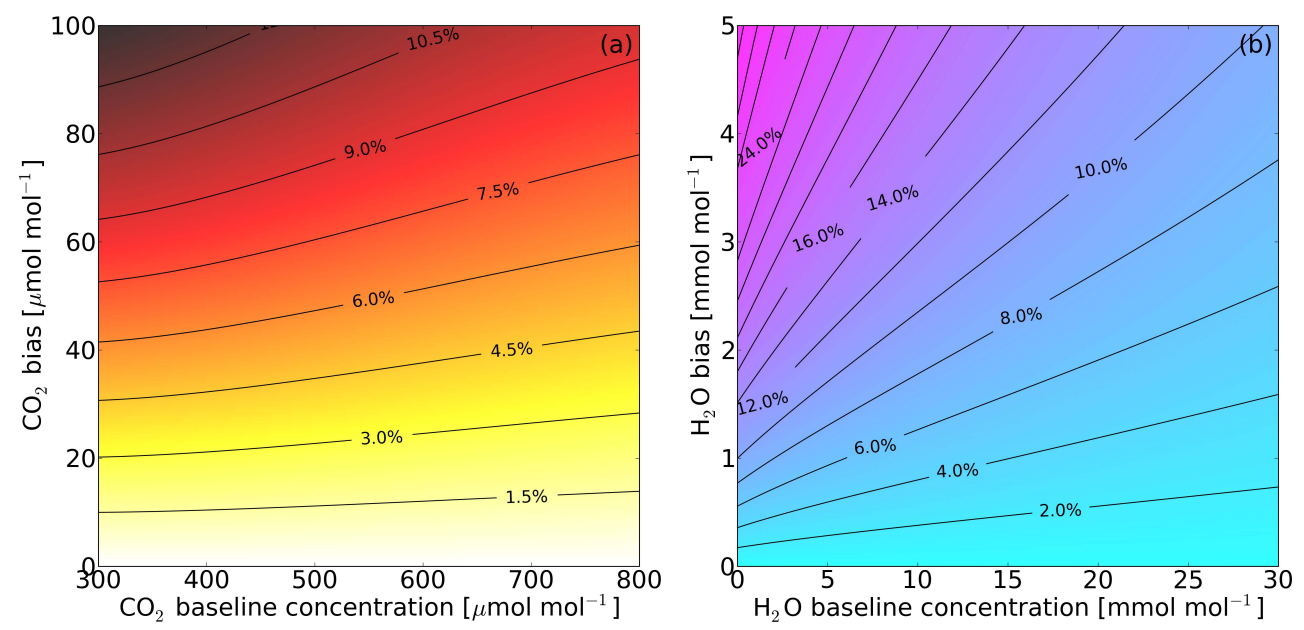

Fig. 3. Relative error $\epsilon_{f}$ in the estimation of a $0.1 \mu \mathrm{mol} \mathrm{mol}^{-1} \mathrm{CO}_{2}$ concentration fluctuation (a) and of a $0.1 \mathrm{mmol} \mathrm{mol}^{-1} \mathrm{H}_{2} \mathrm{O}$ concentration fluctuation (b) as a function of the baseline concentration ( $x$ axis) and of the concentration bias ( $y$ axis).

corresponding calibration curve in environmentally relevant ranges. $\epsilon_{f}$ is generally higher at low concentrations, because the curvature of the calibration curves changes more rapidly at lower values than at higher values. Not shown in the plot, for a given calibration curve, the error pattern is almost identical regardless of the magnitude of concentration fluctuations over the tested ranges of $0.01-2.00 \mu \mathrm{mol} \mathrm{mol}^{-1}\left(\mathrm{CO}_{2}\right)$ and $0.01-2.00 \mathrm{mmol} \mathrm{mol}^{-1}\left(\mathrm{H}_{2} \mathrm{O}\right)$. This happens because the calibration curve can be well approximated with a straight line for small deviations around any particular concentration; however, the slope of the deviation depends on the calibration curve itself. Thus, these are not universal but unit-specific plots. Plots like these can be drawn for any instrument with curvilinear response using Eq. (17) and the calibration curves provided by the manufacturer.

\subsubsection{Errors in $\mathrm{CO}_{2}$ and $\mathrm{H}_{2} \mathrm{O}$ fluxes}

Equation (17) provides a tool for quantification of errors in the estimation of turbulent fluctuations of gas concentrations. However, it does not show in any straightforward way how this error propagates into the corresponding fluxes. It cannot be assumed that the same error is plainly transferred to fluxes, because flux estimation with the eddy-covariance method involves several computation steps, where mean concentrations and variances of different gases interact in a complex manner. As an example, in the WPL term for $\mathrm{CO}_{2}$ fluxes $\left(F_{c}, \mu \mathrm{mol} \mathrm{m}{ }^{-2} \mathrm{~s}^{-1}\right)$, not only the variance of $\mathrm{CO}_{2}$ is concerned, but also the variance of $\mathrm{H}_{2} \mathrm{O}$, as well as the mean concentration of both gases (see, e.g. Burba et al., 2012; Ibrom et al., 2007b; Webb et al., 1980). Water vapour concentration is used in the calculation of air density (which is used in all flux equations; Aubinet et al., 2012) as well as in the humidity correction of sensible heat fluxes (Schotanus et al., 1983), where also $\mathrm{H}_{2} \mathrm{O}$ variance plays a role. In addition, we stress that concentration errors can act in different directions, partially offsetting each other. For example, positive biases in $\mathrm{CO}_{2}$ and $\mathrm{H}_{2} \mathrm{O}$ concentrations, leading to increased covariances with w, partially compensate each other in the WPL term for $F_{c}$ when $F_{c}$ and $L E$ are of opposite sign.

In order to investigate how concentration errors propagate through a typical eddy-covariance processing sequence to contaminate fluxes, we modified the EddyPro software (www.licor.com/eddypro) to simulate the effect of artificial biases introduced in real eddy-covariance data. Because the bias must be introduced at the absorptance level, the simulation requires as an input the instrument calibration curve $F$, which is then numerically inverted to provide a polynomial function used to convert gas measurements into raw absorptances. Data of air pressure and water vapour mole fraction in the optical path are needed in this step to calculate the equivalent pressure (Eq. 12). In addition, gas measurements may need to be converted using the ideal gas law, to match the measurement type in which the calibration curve is provided, either number density (Eq. 2) or (dry) mole fraction (Eq. 3). In this case, additional data of air temperature in the optical path are required. Once high-frequency absorptance time series have been thus created, Eq. (10) can be inverted to simulate $a_{\mathrm{m}}$ starting from $a$ and from the prescribed artificial bias $a_{0}$. Data are then converted back to density or mole fraction, and are thus ready for being used in a conventional eddy-covariance processing. Fluxes so obtained can be finally compared to fluxes obtained from original raw data. Note that any potential (unknown) bias affecting the original raw data (and hence the original fluxes) would be irrelevant in this simulation design.

In a first simulation, we chose data for a specific midday half hour from a forest site, providing large fluxes $(\mathrm{Fc} \approx$ $-23 \mu \mathrm{mol} \mathrm{m}{ }^{-2} \mathrm{~s}^{-1} ; L E \approx 210 \mathrm{~W} \mathrm{~m}^{-2}$ ), at average concentrations of about $375 \mu \mathrm{mol} \mathrm{mol}^{-1}\left(\mathrm{CO}_{2}\right)$ and $13 \mathrm{mmol} \mathrm{mol}^{-1}$ 

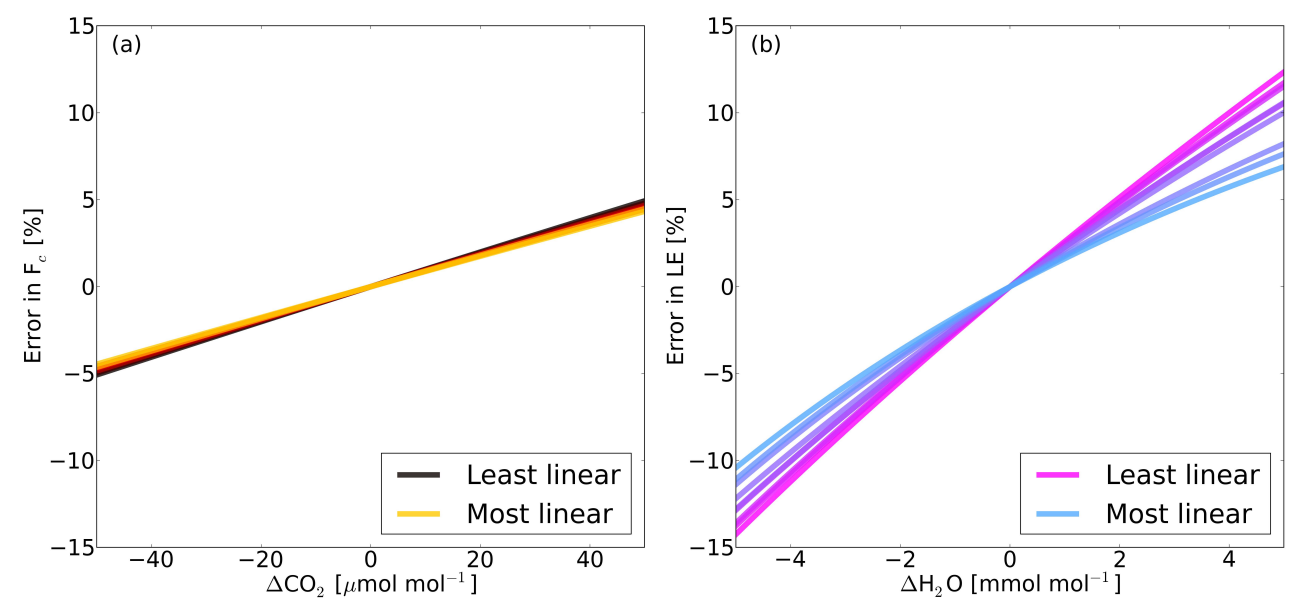

Fig. 4. Percentage errors ( $y$ axis) in $F_{\mathrm{c}}$ (a) and $L E$ (b) resulting from various amounts of concentration biases ( $x$ axis) applied on a typical midday half hour of raw eddy data, characterized by $F_{\mathrm{c}} \approx-23 \mu \mathrm{mol} \mathrm{m}-2 \mathrm{~s}^{-1} ; L E \approx 210 \mathrm{~W} \mathrm{~m}^{-2}$ and average concentrations of $375 \mu \mathrm{mol} \mathrm{mol}^{-1}$ $\left(\mathrm{CO}_{2}\right)$ and $13 \mathrm{mmol} \mathrm{mol}^{-1}\left(\mathrm{H}_{2} \mathrm{O}\right)$.

$\left(\mathrm{H}_{2} \mathrm{O}\right)$, and iteratively applied varying amounts of absorptance biases, corresponding to plausible concentration errors as derived from observation of long-term $\mathrm{CO}_{2} / \mathrm{H}_{2} \mathrm{O}$ concentration data sets available in the FLUXNET community and regional database (e.g. www.europe-fluxdata.eu), and from our field experience (see also Sect. 3.1). We repeated this simulation for nine different calibration curves (for both gases), chosen to represent the curvature distribution of a population of more than two hundred LI-7200 calibration curves. In particular, we chose the curves corresponding to $1 \%, 5 \%, 10 \%, 25 \%, 50 \%, 75 \%, 90 \%, 95 \%$ and $99 \%$ percentiles of curvature, with $1 \%$ having the greatest and $99 \%$ the least curvature. The aim of this exercise is twofold: (1) assessing the dependency of the flux error on the concentration bias and (2) evaluating the extent to which this relation depends on the actual calibration curve chosen. We are thus providing a prediction of how different instrumental units used in the eddy-covariance network respond to concentration biases.

Results are summarized in Fig. 4, where two main features can be seen: first, the error in fluxes is consistently lower than the error in the individual concentration fluctuations analysed in the previous section (Fig. 3). In our specific case, this is the result of the compensating effect of an artificially increasing water vapour density, which implies a decreasing air density: for each half hour, the biased flux is the result of an increased covariance and a reduced air density, multiplied as per Eq. (1). Second, curves are both more curved and more variable for $\mathrm{H}_{2} \mathrm{O}$ than for $\mathrm{CO}_{2}$. This confirms that a universal relation cannot be established and that any quantification of the error or attempt of correction must rely on knowledge of the specific calibration curve for the deployed instrument. This also highlights the importance of correcting this error when different instruments - even if of the same model - are compared, or used jointly at the same site. As expected, the error is smaller for instruments with the least curvature and increases with increasing curvature. Note, however, that the Pearson coefficient evaluates the linearity of a curve in its entirety, not for each point or sector. Hence, it is not surprising that the error curves of Fig. 4 do not show rigorous symmetry or mutual monotonicity.

Figure 4 illustrates clearly the dependency on the calibration curve and serves as a direct estimation of flux errors as a function of concentration errors; however, from Fig. 3 we know that such error is expected to change with the baseline concentrations and not to depend strongly on the magnitude of concentration fluctuations (hence, on flux intensity). In order to get a more comprehensive picture of how errors vary over realistic environmental regimes, we used a $1 \mathrm{yr}$ (2005) time series of raw data from the forest site of Sorø, in Denmark (Pilegaard et al., 2011). We used the median curvature calibration curves (as in Fig. 4) and repeatedly applied a range of absorptance biases in such a way that each bias amount was applied several times along the year, encompassing periods of high and low concentrations, as well as high and low flux intensities. We can then evaluate how different absorptance biases (or corresponding concentration errors) affect fluxes at different baseline concentrations and with fluctuations of varying intensity.

Figure 5a confirms that the error in $F_{c}$ is weakly dependant on the baseline $\mathrm{CO}_{2}$ dry mole fraction, a result that matches that of Fig. 4. On the contrary, the error in $L E(5 \mathrm{~b})$ varies strongly with the baseline $\mathrm{H}_{2} \mathrm{O}$ mole fraction, with such dependency being larger for larger biases. The reason for this is that the change from 2.5 to $20 \mathrm{mmol} \mathrm{mol}^{-1} \mathrm{H}_{2} \mathrm{O}$ represents about $29 \%$ of the full scale calibration range for water vapour, but the change from 350 to $440 \mu \mathrm{mol} \mathrm{mol}^{-1}$ is only about $3 \%$ of full scale for $\mathrm{CO}_{2}$; thus water vapour calibration curves exhibit much greater curvature than corresponding $\mathrm{CO}_{2}$ calibration curves over these ambient ranges. 


\subsection{Field experiment}

With the aim of investigating the effect of actual contamination on field data, we used data from an experiment setup in the context of the ICOS project (www.icos-infrastructure.eu) to study uncertainties in eddy-covariance measurements due to instrument deployments and maintenance choices (Arriga et al., 2014). Within this experiment, an LI-7200 and an LI7000 were operated in parallel for a period of 45 days at an agricultural site particularly prone to airborne pollution by mineral particulate matter mobilized by agricultural activities. The LI-7000 was protected with a particulate filter (Pall Gelman $1 \mu \mathrm{m}$ PTFE) at the inlet of the sampling line to avoid cell contamination, but airborne particulates were allowed to enter the air circuit of the LI-7200 analyser and possibly accumulate on the window of the optical cell. The two analysers shared the same wind and sonic temperature data, collected by an HS-50 sonic anemometer (Gill Instruments Ltd., Lymington, UK). The sampling volume was placed about $3.5 \mathrm{~m}$ above a flat and virtually bare surface (grassland harvested and at the end of the growing season), extending for at least $250 \mathrm{~m}$ in the direction of prevailing winds.

On day one of the data set that we will consider, the concentration mismatches between the instruments (LI7000 minus LI-7200) when measuring ambient air were $-20 \mu \mathrm{mol} \mathrm{mol}^{-1}\left(\mathrm{CO}_{2}\right)$ and $0 \mathrm{mmol} \mathrm{mol}{ }^{-1}\left(\mathrm{H}_{2} \mathrm{O}\right)$. The $\mathrm{CO}_{2}$ offset was completely explained by the fact that calibration and cell cleaning of the LI-7200 occurred 7 days before the beginning of our data set. During those 7 days some contamination and concentration drift occurred.

Instruments were left unmaintained in the field for an additional 45 days, and at the end of this period a calibration check was performed before cleaning the instruments, with the result that $\mathrm{CO}_{2}$ dry mole fractions and $\mathrm{H}_{2} \mathrm{O}$ mole fractions from the LI-7200 were biased by about $70 \mu \mathrm{mol} \mathrm{mol}^{-1}$ and $11 \mathrm{mmol} \mathrm{mol}^{-1}$, respectively, while the LI-7000 measurements were virtually unbiased. It is important to note that after cleaning the cell of the LI-7200 the offset reduced to less than $1 \mu \mathrm{mol} \mathrm{mol}^{-1}\left(\mathrm{CO}_{2}\right)$ and $0.1 \mathrm{mmol} \mathrm{mol}^{-1}\left(\mathrm{H}_{2} \mathrm{O}\right)$, confirming that the instrumental drift was entirely explained by the obstruction of the optical path by airborne particulates deposited on the instrument windows.

Adopting fluxes from a filtered LI-7000 as a reference allowed us to study how fluxes measured with an unfiltered LI-7200 are affected by absorptance biases that may occur due to the accumulation of particulates in the optical cell.

\subsection{Correction procedure during post-field data processing}

Based on the previous analysis, we devised a correction procedure to compensate for absorptance biases before calculating fluxes, to mitigate and potentially eliminate this source of systematic errors. In essence, the correction procedure is the inverse of the simulation described in Sect. 2.1.2. It con- sists in elaborating calibration-check data and dates to create a time series of absorptance biases. This is done by converting the offset between measured and reference concentrations into the corresponding zero offset absorptance biases, and distributing the biases linearly between each pair of adjacent calibration dates (thereby assuming a constant bias increase), to obtain an absorptance bias value for each flux period. Then, raw high-frequency time series of gas densities (or concentrations) are converted to raw absorptances $\left(a_{\mathrm{m}}\right)$. At this stage, Eq. (10) can be used to correct $a_{\mathrm{m}}$ for the bias $\left(a_{0}\right)$ estimated for each time period and to calculate correct absorptances $(a)$, which are then converted back to densities or concentrations. Such corrected time series are then used for all calculations, including fluxes. Again, in all cases, the calibration curve of the specific instrument is used to transform from/to absorptances. Note that, if raw data are only available as (dry) mole fraction, suitable temperature and pressure measurements in the optical path may be needed to convert data to number densities before the calibration curve can be used to calculate raw absorptances. Air pressure data are also needed to account for pressure effects (Eq. 12). For this reason, as a first recommendation, we suggest IRGA users collect high-frequency number densities (LI-7200, LI7500(A)) or mole fractions (LI-7200, LI-7000, LI-6262), and high-frequency raw absorptances if they can, along with temperatures and pressures. Note that either number densities or mole fractions can be used with the LI-7200, but the calibration function is in number density.

\section{Results and discussion}

\subsection{Experimental results}

Figure 6 compares the time evolution (colours) of $\mathrm{H}_{2} \mathrm{O}$ and $\mathrm{CO}_{2}$ mole fractions measured by the two instruments, along with the corresponding $L E$ and $F_{c}$ values. Note that fluxes presented hereafter are fully corrected, including careful correction for spectral attenuations, a major source of flux losses in closed-path systems and a potential source of bias when comparing closed-path setups. Spectral losses were assessed following an established procedure (Ibrom et al., 2007a) and corrected after Fratini et al. (2012).

Water vapour concentrations (6a) diverge as time progresses, with the LI-7200 giving increasingly higher measurements than the LI-7000. Correspondingly, from the initial agreement (dark blue), $L E$ fluxes (6b) tend to depart as time proceeds with the LI-7200 providing substantially higher estimates towards the end of the experiment $(\approx 23 \%)$, with an average of $\approx 9 \%$ over the whole period. Carbon dioxide concentrations (6c) show a similar pattern, although the evolution of $F_{c}(6 \mathrm{~d})$ is less informative, because most fluxes were of low intensity.

Figure 6 also shows that changes in concentration deviations occurred mostly as a relatively small number of sudden 

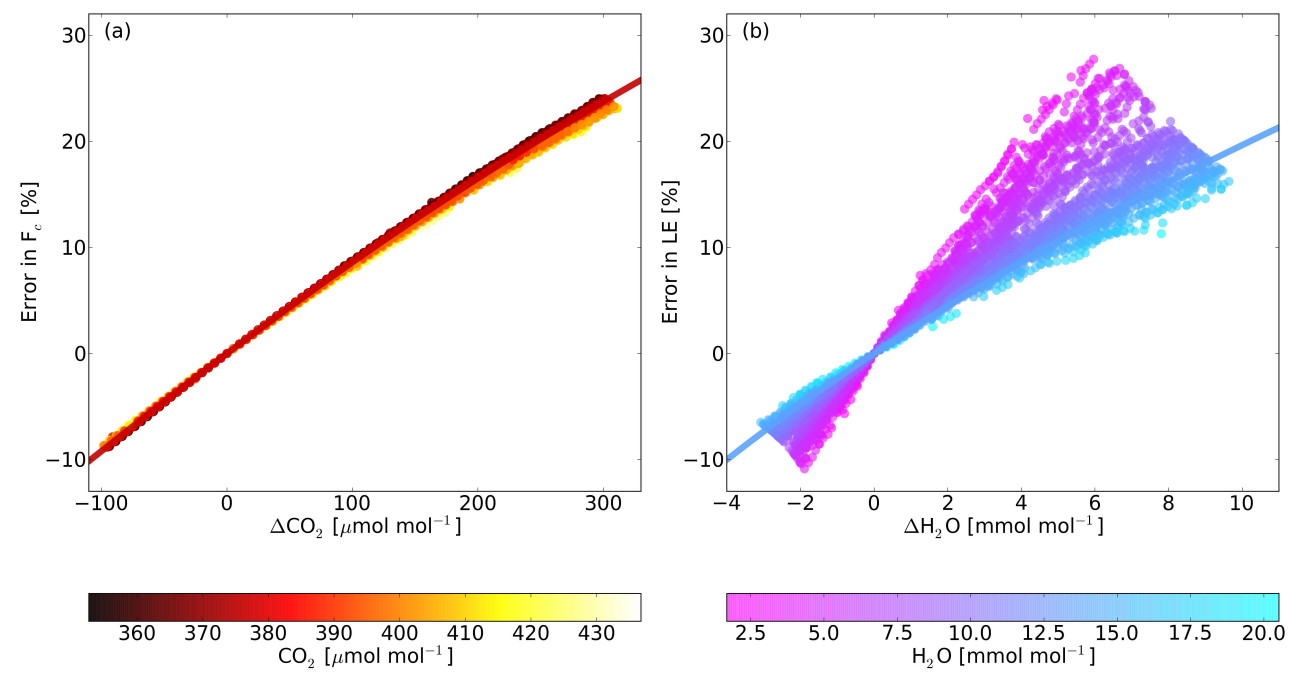

Fig. 5. Percentage errors ( $y$ axis) in $F_{\mathrm{c}}$ (a) and $L E$ (b) resulting from various amounts of concentration biases ( $x$ axis) applied to 1 yr (2005) of raw eddy data from the forest site of Sorø, Denmark. The two error curves from Fig. 4 corresponding to the same calibration function used for the $1 \mathrm{yr}$ simulation are also shown here. $\Delta \mathrm{CO}_{2}$ and $\Delta \mathrm{H}_{2} \mathrm{O}$ are biases, and colours give varying baseline concentrations.

changes in both gases simultaneously rather than in a continuous fashion. This suggests that - in this specific case deviations are mostly due to extemporary depositions, such as those deriving from agricultural activities, rather than to continuous deposition of background ambient aerosols. This occurrence limits the accuracy of the procedure, which, as explained, assumes a constant increase of the bias with time. This aspect will be further discussed in Sect. 3.2.

In order to understand the extent to which biases in $\mathrm{H}_{2} \mathrm{O}$ concentration measured by the LI-7200 explain $L E$ discrepancies, and to test our theoretical approach, in Fig. 7 we present relative flux differences between the two instruments plotted as a function of concentration differences, and compare it to the numerical simulation of flux errors vs. concentration biases. The experimental data and numerical simulation results follow the same pattern suggesting that, to a large extent, the concentration bias explains the observed flux differences. Despite all factors potentially affecting the direct comparison between field measurements of two rather different eddy-covariance deployments (different instruments, sampling lines, positions, sources of random errors, etc.), not only do observed flux errors fall in the range predicted in Fig. 5, but also the dependency on the baseline concentration matches fairly well, reflecting a sound understanding and representation of the origin of errors in flux estimates. From the results in Fig. 7, we expect our correction procedure to be able not only to reduce the systematic difference between the two flux series of the LI-7200 and LI-7000, but also to maintain or increase the coefficient of determination, although different sources of random errors hinder the comparability of the two systems, and make the small variations of the $r^{2}$ less informative.

\subsection{Evaluation of the correction procedure}

The results described in the previous section provide a good basis for testing the correction procedure. Figure 8 shows the effect of the correction applied to the same data used in Fig. 6. Left-hand plots show that for water vapour (8a), the correction procedure is substantially successful in moving the concentration measurements made with the unfiltered LI7200 into close agreement with those made with the LI-7000, which measured filtered air. The match is greatly improved also for $\mathrm{CO}_{2}$ concentrations (8c). Although $\mathrm{CO}_{2}$ residual discrepancies appear larger than $\mathrm{H}_{2} \mathrm{O}$ ones, it should be noted that the relative range of variation of $\mathrm{CO}_{2}$ is much smaller than that of $\mathrm{H}_{2} \mathrm{O}$. Thus $\mathrm{CO}_{2}$ differences are essentially magnified by the fact that its axes encompass (relatively) smaller ranges. Residual concentration differences between the two instruments and for both gases are due to a partial violation of the assumption used in the correction procedure that the contamination and consequent bias accumulate uniformly with time between calibrations, which underlies the linear model of absorptance bias accumulation. The more the actual drift pattern deviates from a uniform increase, the less the correction is accurate. For the same reason, it is to be expected that an assessment of the drift on a fine timescale - finer than the 45 days used here - would improve the effectiveness of the correction. Right-side plots of Fig. 8 show that the correction greatly improves the agreement of $L E(8 \mathrm{~b})$. Note that not only the whole flux time series is now very close to the $1: 1$ line, but also that the random error was reduced, with $r^{2}$ increasing from 0.944 to 0.966 after the correction. We stress here that the correction procedure is not informed, at any level, by knowledge of the reference fluxes; the only input to the correction was the gas concentration offset in the 

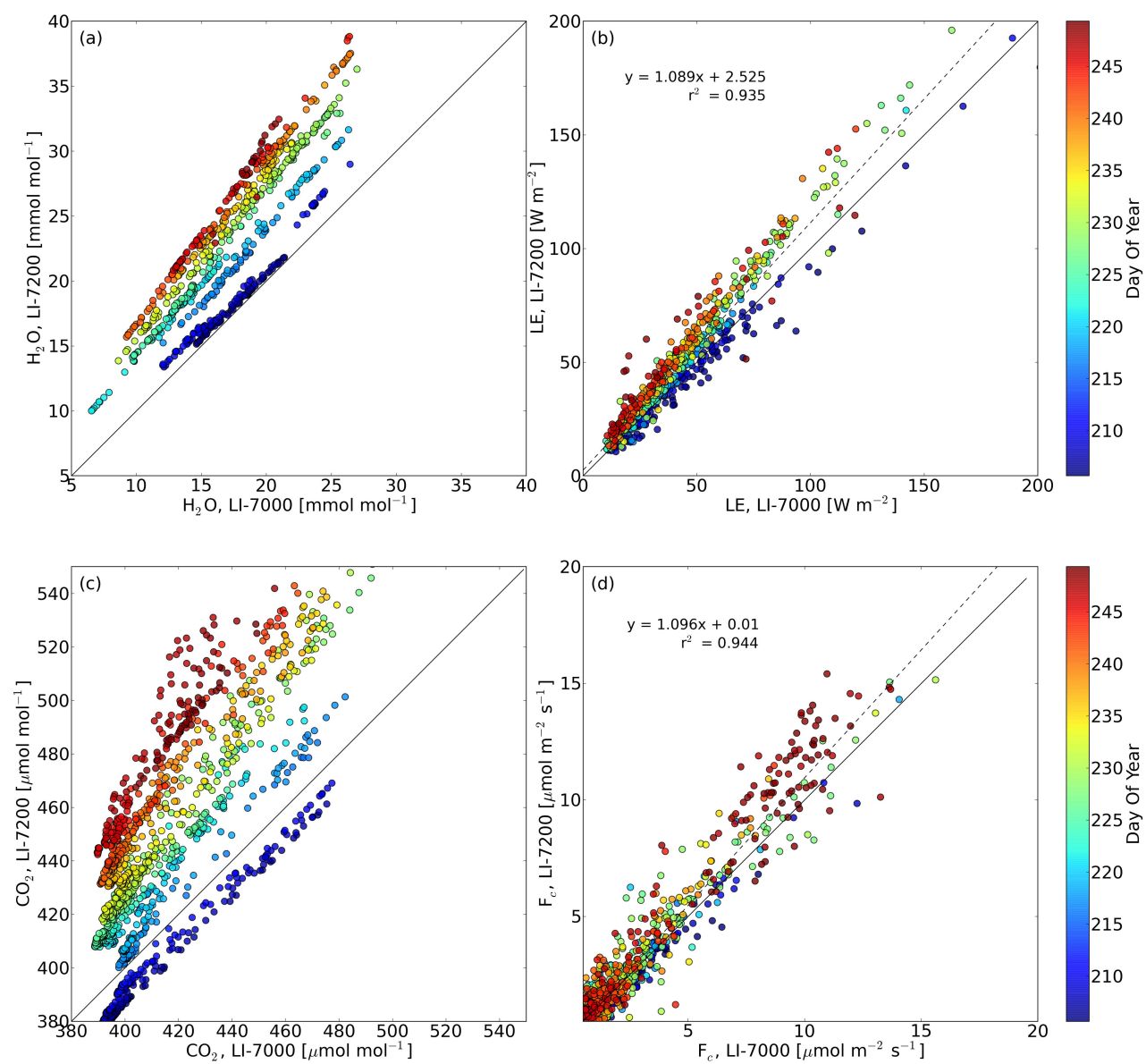

Fig. 6. Comparison of $\mathrm{H}_{2} \mathrm{O}$ (a) and $\mathrm{CO}_{2}$ (c) mole fractions as measured by the LI-7000 and LI-7200 and corresponding $L E$ (b) and $F_{\mathrm{c}}$ (d) values. Colour represents progressing time from the beginning of the experiment.

instruments after 45 days of autonomous data collection. The significant and consistent improvement brought by the correction, along with its simple and sound theoretical background, provides confidence in its analytical formulation and actual implementation. An improvement is achieved also for $F_{c}$, with a regression slope reducing from 1.096 to 1.059 (8d).

\subsection{Discussion of main drift sources and implications for field operations}

\subsubsection{Effect of temperature sensitivity on concentration measurements}

One of the sources of absorption biases is the temperature dependency of instrumental readings. This arises due to a collection of minor phenomena including thermal expansion/contraction of instrument components that slightly change the geometry of the system. In addition, performance of the radiation source and detector, as well as electronic components, can vary slightly with temperature. At produc- tion, manufacturers may include algorithms in the instrument firmware to compensate for the ensemble of such dependencies as assessed in a temperature chamber (e.g. LI-7200, LI7500). However, response to temperature can vary as conditions change over time. Therefore manufacturers typically specify an expected range of typical or maximal concentration deviation per degree Kelvin that is assured to hold for the entire lifetime of the instrument. As a consequence of temperature sensitivity, in the presence of a constant gas concentration, a gas analyser in the field will provide a concentration reading that changes in time, correlating to a certain degree with ambient temperature cycles. We note here that a portion of the residual offsets observed at the end of the field experiment (Sect. 2.2) can actually be a consequence of performing the calibration check at a temperature different from the one at which the previous field calibration was performed.

In typical conditions, such variations are slow enough not to affect the estimation of turbulent fluctuations directly to a large extent. Nonetheless, by means of a numerical simulation, Metzger (2013) showed that the magnitude of individual half-hourly flux observations may be disturbed if 

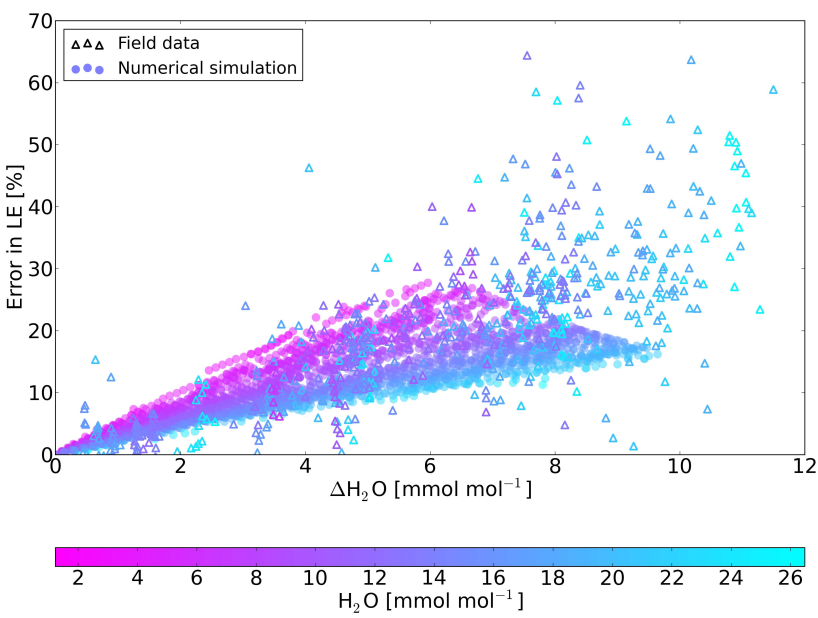

Fig. 7. Latent heat flux error as a function of $\mathrm{H}_{2} \mathrm{O}$ concentration bias, for the LI-7200 field data and for the numerical simulation performed in Sect. 2.1.2. For the field data, flux errors and concentration biases are calculated taking the corresponding LI-7000 data as a reference. Colours indicate average baseline concentration.

strong temperature gradients occur and suggested that, where possible, a recurring re-characterization of each individual IRGA in a climate chamber might better constrain instrument drifts and thus reduce direct effects. Where available, the fast IRGA data could also be based on simultaneously measured slow, though high-precision, high-accuracy gas analyser readings, e.g. through complementary filtering approaches (e.g. Metzger et al., 2012).

In addition, as temperature changes, the measured absorptance changes and fluxes are indirectly affected for the reasons explained in this paper. As an example, if a field calibration is performed at a temperature of $20^{\circ} \mathrm{C}$ and a constant gas concentration is passed through the analyser, in absence of other factors affecting the measurements, we should expect the analyser to provide the correct concentration stably at $20^{\circ} \mathrm{C}$, but to provide diverging concentration as temperature departs from this value. As mentioned, the magnitude of such deviation may change over time unpredictably for a given unit, but they are expected to be within the manufacturer's specifications.

It is unlikely such a source of error can be corrected reliably using the procedure proposed in this paper, unless a paired (temperature-regulated) gas analyser is used to continuously provide a reference for accurate measurement of gas concentrations. Fortunately, the order of magnitude of these errors is relatively small. As an extreme example, for a departure of $30 \mathrm{~K}$ from the calibration temperature, the LI-7200 manual specifies a maximum concentration error of about $10 \mu \mathrm{mol} \mathrm{mol}^{-1}\left(\mathrm{CO}_{2}\right)$ and $1.7 \mathrm{mmol} \mathrm{mol}^{-1}\left(\mathrm{H}_{2} \mathrm{O}\right)$, obtained as the sum of the maximal drifts for both zeros and spans, evaluated at the nominal concentrations of $370 \mu \mathrm{mol} \mathrm{mol}^{-1}$ $\left(\mathrm{CO}_{2}\right)$ and $20 \mathrm{mmol} \mathrm{mol}^{-1}\left(\mathrm{H}_{2} \mathrm{O}\right)$. Based on Fig. 4, the ex- pected maximum flux error would be of the order of $\pm 1 \%$ for $F_{c}$ and $\pm 3 \%$ for $L E$. In reality, we can expect actual concentration deviations to be anywhere between zero and these upper limits, and the flux errors to vary accordingly. A couple of good practices of field deployment follow directly from these considerations. First, reducing the thermal excursion of the analyser body (for example by shading or coating) directly mitigates the problem at the source. Second, we suggest performing field calibration at a temperature that minimizes the temperature departures, on average, during the periods of interest. As an example, if nocturnal $L E$ fluxes are not of interest, a suitable temperature for $\mathrm{H}_{2} \mathrm{O}$ field calibration would be the median daytime temperature of the period.

\subsubsection{Deposition and accumulation of pollutants in the optical path}

As we have seen, dirt deposition in the optical path can lead to large absorptance biases and significant flux errors. The importance of this source of errors depends dramatically on the environment where the instrument is used. For example, crop fields such as the one where we performed our tests are more prone to airborne pollution due to agricultural operations. Coastal and urban landscapes, as well as ecosystems with massive production of pollens, are other examples of environments where airborne pollution might be particularly relevant. The problem of cell contamination can be mitigated at the source by (1) positioning the analyser in such a way to reduce the chances that particulate matter accumulates on the optical windows. For open-path IRGAs, the suggestion is to incline the head about $10-15$ degrees from the vertical, so as to facilitate water drainage. This also helps with contamination, because a dryer surface will tend to detain particulate matter less. (2) Introducing a particulate filter in the intake line (closed-path instruments) prevents contaminants from entering the optical cell. (3) Adapting the instrument cleaning schedule to the rate at which contamination accumulates, which varies from site to site, will also help reduce measurement biases and the need for correction (see also Sect. 3.3.4).

\subsubsection{Field calibration operations}

Several potential pitfalls, often overlooked, are hidden in field calibration operations. The procedure of field calibration, performed with the aim of mathematically compensating observed instrumental drifts, relies on the availability of accurate reference gases. Zero calibrations are performed using a dry, $\mathrm{CO}_{2}$-free gas, which can be obtained from ambient air using chemical scrubbers, or from cylinders of zero grade gas. When using scrubbers, it is important to follow the guidelines of the manufacturers, to assure complete elimination of $\mathrm{H}_{2} \mathrm{O}$ and $\mathrm{CO}_{2}$ from ambient air. When using cylinders, it is important to realize that, for example, a cylinder of standard grade nitrogen might actually contain as much as 

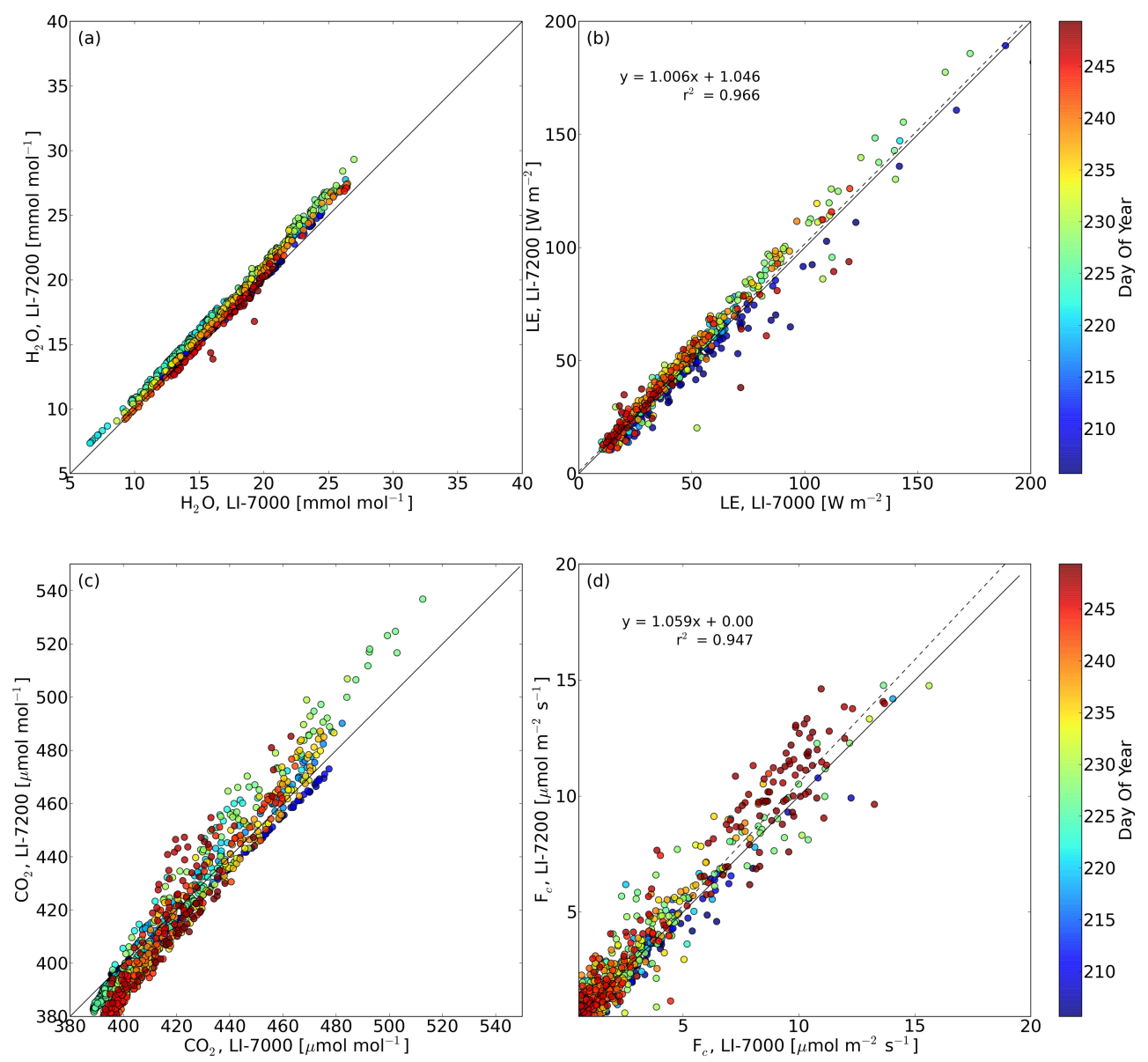

Fig. 8. Comparison of $\mathrm{H}_{2} \mathrm{O}$ (a) and $\mathrm{CO}_{2}$ (c) mole fractions as measured by the LI-7000 and LI-7200 and corresponding $L E$ (b) and $F_{\mathrm{c}}$ (d) fluxes after compensation of concentration biases. Colour represents progressing time from the beginning of the experiment.

$20 \mu \mathrm{mol} \mathrm{mol}^{-1}$ of $\mathrm{CO}_{2}$, which would imply a flux error of about $2.5 \%$ (Fig. 3a). Similarly, attempting to perform $\mathrm{H}_{2} \mathrm{O}$ zero and span calibrations in the field exposes one to serious risks of mis-calibration, since water vapour strongly adsorbs and desorbs from system surfaces, and thus requires constant temperature, ventilation and radiation loads, over long equilibration times before the readings stabilize. In general, if reliable calibration standards are not available, or if there is not enough time or sufficiently stable conditions to do the job properly, it is better not to perform the field calibration at all: a less frequent but more careful lab calibration would provide the information needed to back-correct collected data with the procedure proposed in this paper. This is especially true for water vapour. In addition, we recommend that for the reasons already given, field calibration checks should be performed at temperatures comparable to the last calibration temperature. Otherwise, an appropriate degree of uncertainty must be accepted when assessing instrumental drifts.

\subsubsection{Setup recommendations to track and correct concentration drifts and biases}

Here we have attributed instrumental drifts largely to the effects of contamination, which can have differential effects on the sample and reference paths in the optical system. We showed that measurement accuracy was restored without any other adjustments, when an LI-7200 was cleaned after a 45-day continuous deployment, confirming that the drift was due to contamination and not to inherent instability of the instrument. Further, we showed that correcting for zero offsets approximately as they occurred in time led to substantial improvement in accuracy of $F_{c}$ and $L E$ as measured by agreement with fluxes measured using a filtered LI7000. These observations suggest three approaches to mitigate the effects of contamination: (1) always record a full set of absorptances, pressures, temperatures, and concentrations, to allow data to be recalculated and fluxes reprocessed at a later date, if necessary; (2) clean the instrument on a regular schedule, or when contamination or drifts are detected; 
(3) check instrument zero periodically. The work presented here suggests that the most relevant action to detect and correct instrument drift due to contamination is to check zero using dry $\mathrm{CO}_{2}$-free gases. When the use of a tank (e.g. $\mathrm{N}_{2}$ or dry $\mathrm{CO}_{2}$-free air) is difficult, for example for logistic or energy limitations, one can generate dry $\mathrm{CO}_{2}$-free air at the site using suitable chemicals to check instrument zeros at appropriate intervals. Our results imply that workable intervals might be once every day to once every few weeks, depending on the contamination rate. Appropriate intervals will vary from site to site and can be chosen with considerable latitude. Chemical scrubbers are also useful and sometimes suggested for tanks of $\mathrm{CO}_{2}$-free air or $\mathrm{N}_{2}$ to ensure a completely dry and $\mathrm{CO}_{2}$-free airstream for checking zero. For closed-path instruments, zero checks might be performed automatically and frequently using a pump and switching system to reduce interpolation errors, or manually during site visits; for openpath instruments, zero checks would be performed manually.

Another approach might be to validate system performance using a second gas analyzer with filtered intake and low flow rates to ensure unbiased $\mathrm{CO}_{2} / \mathrm{H}_{2} \mathrm{O}$ measurements, which would allow a continuous assessment of any concentration bias in the eddy-covariance instrument. As an example, stations featuring a $\mathrm{CO}_{2} / \mathrm{H}_{2} \mathrm{O}$ profile system may already have such suitable concentration references. Drawbacks of this approach are (1) the uncertainty due to the fact that instruments may be measuring at different locations and (2) the fact that differences in measured ambient concentrations may be the result of a zero and a span drift, with no obvious means to discriminate them. For these reasons we suggest that appropriate maintenance along with periodic direct test of the zero drift is the best solution to address the problem.

\section{Conclusions}

We have pointed out that the physical relationship between absorber concentration and broadband absorption in NDIR gas analysers is inherently non-linear. As a consequence, biases in concentration measurements imply errors in resulting eddy-covariance fluxes, but the relative errors in the fluxes are smaller than relative errors in the concentrations. The same concept can be generalized to any gas analyser with a nonlinear relation between the measured quantity and the density or concentration of the gas of interest, and indeed to any nonlinear instrument intended for the measurement of turbulent fluctuations, possibly including sonic anemometers for the measurement of wind components and sonic temperature.

We found that, while errors in gas concentration fluctuations can be characterized starting from knowledge of only the zero offset and calibration curve (Fig. 3), errors resulting from the eddy-covariance flux calculations are less predictable a priori, because they depend on nontrivial interactions between mean concentrations and variances of the gas under consideration, and of water vapour, at a minimum. The procedure proposed, which compensates for measurement biases at the raw data level before any other processing step, avoids this problem, as all interactions occur in subsequent phases of the flux calculation and correction sequence.

By definition, the correction fades to zero as errors in concentration measurements tend to zero. Thus, we suggest always applying this correction, and in fact including it in the "standard" sequence of eddy-covariance processing. As far as past eddy-covariance data sets are concerned, we note that the only information needed to apply the correction to raw data is the magnitude of the error in the absolute concentrations, generally recorded during field calibrations (and, on the basis of our results, we advise doing so). Thus, it is possible to recalculate fluxes including this correction to evaluate if the problem is relevant at each specific site. Similarly, in light of the increasing interest for synthesis activities where data from multiple sites are used and compared, it is crucial to minimize differences between fluxes measured at different sites due to non-biological factors such as absolute concentration errors and linearity of the calibration curve analysed in this paper. In such situations, we recommend re-processing raw data and applying the correction suggested in this paper, if there are reasons to think that concentration time series could be affected by systematic biases.

If past eddy-covariance raw data are not available and time series show relevant concentration errors, the correction could be applied in a weaker version by establishing error curves as a function of concentration errors, such as those of Figs. 3 or 4, and use that to derive correction factors to apply to each flux value. Though not completely accurate, this strategy is expected to at least reduce the inaccuracy of computed fluxes.

In Sect. 3.2 we noted that a source of inaccuracy in the proposed procedure is the assumption of the linear increase of absorptance bias between consecutive calibration checks. Current work is exploring the possibility of using diagnostics for cell contamination (e.g. signal strength) as an interpolation function to refine the definition of the bias evolution between consecutive calibration checks.

The correction described in this paper will soon be available in the EddyPro software (www.licor.com/eddypro).

\section{Appendix A}

\section{Expressing water vapour concentration}

Mixing ratio is a convenient unit for calculations (e.g. Eq. 1), but it is not strictly comparable for trace gases and water vapour. For trace gases such as $\mathrm{CO}_{2}$, we take mixing ratio to be the mole fraction in dry air (i.e. the mole fraction in moist air divided by $1-\mathrm{e} / P$, where $\mathrm{e}$ is the water vapour pressure). Thus for $\mathrm{CO}_{2}$, the mixing ratio, being equal to dry mole fraction, is proportional to number density and partial pressure in 
dry air, and can be used for calibrations. Similarly, the mixing ratio of water vapour is defined as the water vapour mole fraction in moist air divided by $1-\mathrm{e} / P$, which gives moles of water vapour per mole of dry air. Of course, dry air contains no water vapour, so mixing ratio for water vapour does not equal mole fraction. Thus, for water vapour, mixing ratio is not proportional to number density or partial pressure, making it an unsuitable unit for gas analyser calibrations. Although some instruments can provide output in mixing ratio units, they are calibrated either in number density according to Eq. (2) or mole fraction according to Eq. (3). In this paper, the term concentration will refer to mole fraction in dry air for $\mathrm{CO}_{2}$ and mole fraction in moist air for water vapour.

Acknowledgements. LI-COR wishes to thank the scientists at the University of Tuscia and the ICOS community for their close cooperation, without which this work would have been impossible. The authors also thank J. Welles for useful discussions, N. Arriga, M. Tomassucci, A. Boschi and A. Baiocco for the data acquired in the experiment and A. Ibrom and K. Pilegaard for the raw data acquired at Sorø, and their great work at the Sorø site. D. Papale also wishes to thank the EU projects ICOS and ICOS-INWIRE for their support.

Edited by: E. Falge

\section{References}

Arriga, N., Boschi, A., Tomassucci, M., Fratini, G., and Papale, D.: Uncertainty in eddy-covariance measurements due to instrumental setup and field deployment, in preparation, 2014.

Aubinet, M., Vesala, T., and Papale, D.: Eddy Covariance: A Practical Guide to Measurement and Data Analysis, Springer, Dordrecht Heidelberg London New York, 460 pp., 2012.

Baldocchi, D.: "Breathing" of the terrestrial biosphere: lessons learned from a global network of carbon dioxide flux measurement systems, Aust J. Bot., 56, 1-26, 2008.

Baldocchi, D., Detto, M., Sonnentag, O., Verfaillie, J., Teh, Y. A., Silver, W., and Kelly, N. M.: The challenges of measuring methane fluxes and concentrations over a peatland pasture., Agric. For. Meterol., 153, 177-187, 2012.

Baldocchi, D. D.: Assessing the eddy covariance technique for evaluating carbon dioxide exchange rates of ecosystems: past, present and future, Glob. Change Biol., 9, 479-492, 2003.

Beer, C., Reichstein, M., Tomelleri, E., Ciais, P., Jung, M., Carvalhais, N., Rödenbeck, C., Arain, M. A., Baldocchi, D., Bonan, G. B., Bondeau, A., Cescatti, A., Lasslop, G., Lindroth, A., Lomas, M., Luyssaert, S., Margolis, H., Oleson, K. W., Roupsard, O., Veenendaal, E., Viovy, N., Williams, C., Woodward, F. I., and Papale, D.: Terrestrial Gross Carbon Dioxide Uptake: Global Distribution and Covariation with Climate, Science, 329, 834-838, doi:10.1126/science.1184984, 2010.

Bonan, G., Lawrence, P. J., Keith, W. O., Levis, S., Jung, M., Reichstein, M., Lawrence, D. M., and Swenson, S. C.: Improving canopy processes in the Community Land Model version 4 (CLM4) using global flux fields empirically in- ferred from FLUXNET data, J. Geophys. Res., 116, G02014, doi:10.1029/2010JG001593, 2011.

Burba, G. G., Schmidt, A., Scott, R. L., Nakai, T., Kathilankal, J., Fratini, G., Hanson, C., Law, B. E., McDermitt, D. K., Eckles, R., Furtaw, M., and Velgersdyk, M.: Calculating $\mathrm{CO}_{2}$ and $\mathrm{H}_{2} \mathrm{O}$ eddy covariance fluxes from an enclosed gas analyzer using an instantaneous mixing ratio, Glob. Change Biol., 18, 385-399, doi:10.1111/j.1365-2486.2011.02536.x, 2012.

Detto, M., Verfaillie, J., Anderson, F., Xu, L., and Baldocchi, D.: Comparing laser-based open- and closed-path gas analyzers to measure methane fluxes using the eddy covariance method, Agric. For. Meterol., 151, 1312-1324, 2011.

Fratini, G., Ibrom, A., Burba, G. G., Arriga, N., and Papale, D.: Relative humidity effects on water vapour fluxes measured with closed-path eddy-covariance systems with short sampling lines, Agric. For. Meterol., 165, 53-63, doi:10.1016/j.agrformet.2012.05.018, 2012.

Ibrom, A., Dellwik, E., Flyvbjerg, H., Jensen, N. O., and Pilegaard, K.: Strong low-pass filtering effects on water vapour flux measurements with closed-path eddy correlation systems, Agric. For. Meterol., 147, 140-156, 2007a.

Ibrom, A., Dellwik, E., Larsen, S. E., and Pilegaard, K.: On the use of the Webb-Pearman-Leuning theory for closedpath eddy correlation measurements, Tellus Series B-Chemical and Physical Meteorology, 59, 937-946, doi:10.1111/j.16000889.2007.00311.x, 2007b.

Jamieson, J. A., McFee, R. C., Plass, G. N., Grube, R. H., and Richards, R. G.: Infrared Physics and Engineering, McGrawHill, 1963.

Jung, M., Reichstein, M., Ciais, P., Seneviratne, S. I., Sheffield, J., Goulden, M. L., Bonan, G., Cescatti, A., Chen, J., de Jeu, R., Dolman, A. J., Eugster, W., Gerten, D., Gianelle, D., Gobron, N., Heinke, J., Kimball, J., Law, B. E., Montagnani, L., Mu, Q., Mueller, B., Oleson, K., Papale, D., Richardson, A. D., Roupsard, O., Running, S., Tomelleri, E., Viovy, N., Weber, U., Williams, C., Wood, E., Zaehle, S., and Zhang, K.: Recent decline in the global land evapotranspiration trend due to limited moisture supply, Nature, 467, 951-954, doi:10.1038/nature09396, 2010.

Mahecha, M. D., Reichstein, M., Carvalhais, N., Lasslop, G., Lange, H., Seneviratne, S. I., Vargas, R., Ammann, C., Arain, M. A., Cescatti, A., Janssens, I. A., Migliavacca, M., Montagnani, L., and Richardson, A. D.: Global Convergence in the Temperature Sensitivity of Respiration at Ecosystem Level, Science, 329, 838-840, doi:10.1126/science.1189587, 2010.

McDermitt, D., Burba, G., Xu, L., Anderson, T., Komissarov, A., Riensche, B., Schedlbauer, J., Starr, G., Zona, D., Oechel, W., Oberbauer, S., and Hastings, S.: A new low-power, openpath instrument for measuring methane flux by eddy covariance, Applied Physics B: Lasers and Optics, 102, 391-405, doi:10.1007/s00340-010-4307-0, 2011.

McDermitt, D. K., Welles, J. M., and Eckles, R. D.: Effects of temperature, pressure and water vapor on gas phase infrared absorption by $\mathrm{CO}_{2}$, App. Note \#116. Li-Cor Inc., Lincoln, NE, 1993.

Metzger, S., Junkermann, W., Mauder, M., Beyrich, F., ButterbachBahl, K., Schmid, H. P., and Foken, T.: Eddy-covariance flux measurements with a weight-shift microlight aircraft, Atmos. Meas. Tech., 5, 1699-1717, doi:10.5194/amt-5-1699-2012, 2012. 
Metzger, S.: Comment on "Eddy-covariance flux errors due to biases in gas concentration measurements: origins, quantification and correction" by G. Fratini et al., Biogeosciences Discussions, 10, 2013.

Pilegaard, K., Ibrom, A., Courtney, M. S., Hummelshøj, P., and Jensen, N. O.: Increasing net $\mathrm{CO}_{2}$ uptake by a Danish beech forest during the period from 1996 to 2009, Agric. For. Meterol., 151, 934-946, 2011.

Rannik, U. and Vesala, T.: Autoregressive filtering versus linear detrending in estimation of fluxes by the eddy covariance method, Boundary-Layer Meteorol., 91, 259-280, 1999.

Reichstein, M., Papale, D., Valentini, R., Aubinet, M., Bernhofer, C., Knohl, A., Laurila, T., Lindroth, A., Moors, E., Pilegaard, K., and Seufert, G.: Determinants of terrestrial ecosystem carbon balance inferred from European eddy covariance flux sites, Geophys. Res. Lett., 34, L01402, doi:10.1029/2006GL027880, 2007.

Rothman, L. S., Gordon, I. E., Barbe, A., Benner, D. C., Bernath, P. F., Birk, M., Boudon, V., Brown, L. R., Campargue, A., Champion, J. P., Chance, K., Coudert, L. H., Dana, V., Devi, V. M., Fally, S., Flaud, J. M., Gamache, R. R., Goldman, A., Jacquemart, D., Kleiner, I., Lacome, N., Lafferty, W. J., Mandin, J. Y., Massie, S. T., Mikhailenko, S. N., Miller, C. E., Moazzen-Ahmadi, N., Naumenko, O. V., Nikitin, A. V., Orphal, J., Perevalov, V. I., Perrin, A., Predoi-Cross, A., Rinsland, C. P., Rotger, M., Šimečková, M., Smith, M. A. H., Sung, K., Tashkun, S. A., Tennyson, J., Toth, R. A., Vandaele, A. C., and Vander Auwera, J.: The HITRAN 2008 molecular spectroscopic database, J. Quant. Spectrosc. Radiat. Transfer, 110, 533-572, doi:10.1016/j.jqsrt.2009.02.013, 2009.
Schotanus, P., Nieuwstadt, F., and de Bruin, H.: Temperature measurement with a sonic anemometer and its application to heat and moisture fluxes, Boundary-Layer Meteorol., 26, 81-93, 1983.

Serrano-Ortiz, P., Kowalski, A., Domingo, F., Ruiz, B., and AladosArboledas, L.: Consequences of Uncertainties in $\mathrm{CO}_{2}$ Density for Estimating Net Ecosystem $\mathrm{CO}_{2}$ Exchange by Open-path Eddy Covariance, Boundary-Layer Meteorol., 126, 209-218, 2008.

Webb, E. K., Pearman, G. I., and Leuning, R.: Correction of flux measurements for density effects due to heat and water vapour transfer, Quart. J. Roy. Meteorol. Soc., 106, 85-100, 1980.

Welles, J. M. and McDermitt, D. K.: Measuring carbon dioxide in the atmosphere, Micrometeorology in agricultural systems, Agronomy Monograph, 47, 287-320, doi:10.2134/agronmonogr47.c13, 2005. 